
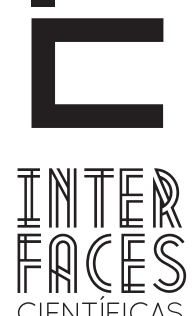

CIENTÍFICAS

HUMANASE SOCIAIS

ISSN IMPRESSO 2316-3348

E-ISSN 2316-3801

DOI - 10.17564/2316-3801.2018v6n3p27-36

\title{
ENTRE A VIDA E A MORTE: CEMITÉRIOS, EM SI PRÓPRIOS, SÃO MUSEUS?
}

BETWEEN LIFE AND DEATH: CEMETERIES, IN THEMSELVES, ARE MUSEUMS?

ENTRE LA VIDA Y LA MUERTE: CEMENTERIOS, EN SÍ MISMOS, SON MUSEOS?

Diego Lemos Ribeiro ${ }^{1}$

Davi Kiermes Tavares ${ }^{2}$

José Paulo Siefert Brahm ${ }^{3}$

\section{RESUMO}

Cemitérios e museus se assemelham por serem construções sociais: lugares fundamentais na construção de memórias e narrativas que entrelaçam o tempo-espaço das sociedades que os originou. Contudo, apesar dessa semelhança, podem os cemitérios ser considerados museus? Ou teriam potencial para sê-lo? A partir desse ideário, o artigo objetiva verificar correlações plausíveis entre as duas instituições, que justifiquem pensá-las com a mesma função social. No intuito de lançar novo olhar e de igual modo discutir sobre o tema museu e cemitério por perspectiva inusual, tem o texto a sua razão de existir. 0 texto reflete a discussão teórica de pesquisas do curso de Mestrado executadas pelos coautores, em fase de conclusão.

\section{PALAVRAS-CHAVE}

Cemitério. Museu. Memória. Identidade. Patrimônio. 


\section{ABSTRACT}

Cemeteries and museums are similar for being social constructions: important places in the construction of memories and narratives that unite the time-space of the societies that originated. However, despite this likeness, can be considered the cemeteries museums? Or would have the potential to do so? From this ideology, the article aims to check plausible correlations between the two institutions, which justify conceive them with the same social function. In order to launch new look, and similarly discuss about the theme museum and graveyard by unusual perspective, has the text to its right to exist. The text reflects the theoretical discussion of research of the masters course run by the coauthors, nearing completion.

\section{KEYWORDS}

Cemetery. Museum. Memory. Identity. Patrimony.

\section{RESUMEN}

Cementerios y museos se asemejan por ser construcciones sociales: lugares fundamentales en la construcción de memorias y narrativas que entrelazan el tiempo-espacio de las sociedades que los originó. Pero, a pesar de esa semejanza, ¿poden los cementerios ser considerados museos? 0 ¿tendrían potencial para serlo? A partir de ese ideario, el artículo objetiva verificar correlaciones plausivas entre las dos instituciones, que justifiquen pensarlas con la misma función social. En el obje- tivo de lanzar nuevo mirar, y de igual modo discutir sobre el tema museo y cementerio por perspectiva inusual, tiene el texto su razón de existir. El texto refleja la discusión teórica de investigaciones del curso de Máster ejecutadas por los coautores, en fase de conclusión.

\section{PALABLAS CLAVE}

Cementerio. Museo. Memoria. Identidad. Patrimonio. 


\section{INTRODUÇ̃̃O}

O cemitério denominado histórico ou tradicional é compreendido pacificamente, nos dias presentes, como lugar de significados e testemunhos dos mais emblemáticos à compreensão da sociedade que o localiza. 0 seu espaço foi e ainda é lugar onde manifestações culturais ancoram; reproduz em seu interior construções interpretativas do imaginário social.

Principalmente na configuração que eclode a partir dos anos 1850 e que, no dizer de um estudioso da questão, caracteriza-se por suas evidências alegóricas, de cenário operáticos e de convulsiva dramaticidade; por desempenharem uma espécie de eficácia simbólica da conservação e da memória, materializada na monumentalidade arquitetônica de seus túmulos individualizados e adornos diversos em torno dos quais se desenvolveram práticas e reproduções simbólicas de naturezas diversas; e ainda ao refletirem visões de mundo de diferentes grupos sociais, expressas por meio de modos socialmente apreendidos de viver que incluem comportamentos, ideias, crenças e valores (MOTTA, 2011, p. 280-281). Tal cemitério (FIGURA 1) será designado como "cemitério oitocentista" visto que a sua existência se origina nos anos de $1800^{1}$.

Figura 1 - Fotografia de parte do acervo do British Cemetery de Salvador, em 2015

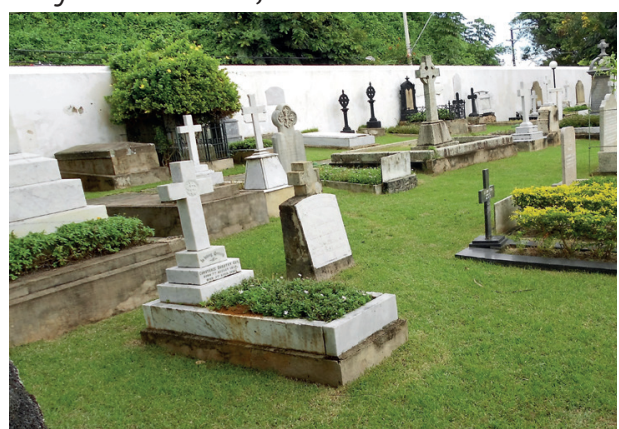

Fonte: Autores.

1 Vale dizer que a historiografia portuguesa considera os espaços funerários consolidados na segunda metade do século XIX pela designação de "cemitérios românticos". A razão disso está calcada no fato de ter este modelo de necrópole atingido seu ápice em meados do século XIX e o Romantismo como movimento estilístico, plástico, literário e musical ter se propagado neste período (ALMEIDA, 2007, p. 125-126).
Por seu turno, os museus (FIGURA 2) são compreendidos como lugares privilegiados de construção, gestão e apropriação de memórias, identidades e bens patrimoniais. Mais do que repositórios de objetos e coisas, são espaços/cenários forjados para proporcionar o encontro entre os sujeitos e suas referências patrimoniais. Enquanto lugares de preservação patrimonial, eles abarcam como funções basilares a coleta, pesquisa, documentação, conservação e comunicação, encadeamentos esses que configuram o processo de musealização (CURY, 2006).

Figura 2 - Fotografia de parte do acervo do Museu Gruppelli, Pelotas/RS, em 2016

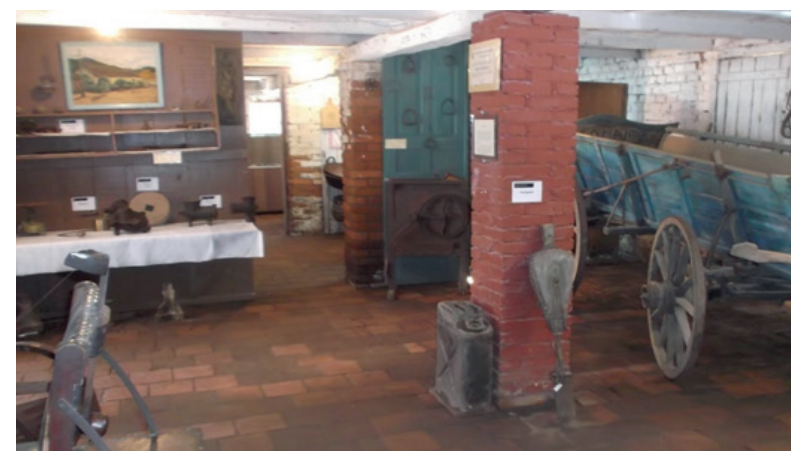

Fonte: Autores.

A musealização, por sua vez, deve ser vista por duas facetas. A primeira, como dito acima, pelo processo sistematizado que redunda nas operações de aquisição, salvaguarda e comunicação. E, em uma segunda via, a musealização é compreendida como fenômeno, em que resulta no deslocamento de olhar sobre os objetos/documentos, subsidiado pelo que a área compreende como "princípio de musealidade" (BRUNO, 2006, p. 56) - que, de forma sumária, seria o olhar que busca um sentido para além da objetividade epidérmica dos objetos/bens patrimoniais. Ambos os pontos de vistas não podem ser pensados de forma estanque; em realidade, o museu processo (o museu-lugar) é uma expressão do museu fenômeno; são, portanto, duas faces do mesmo conceito. 
Assim como os museus, os cemitérios podem ser também lugares de memória, tendo como referência Nora (1993). São espaços que buscam preservar e conservar as memórias do mesmo modo que tem como premissa reafirmar e fortalecer as identidades dos indivíduos e grupos que os visitam ou frequentam. Movidos por uma "vontade de memória" (NORA, 1993, p. 45), o homem/sujeito busca reencontrar-se com o passado nesses lugares, tendo como referência o presente, pois é este quem o modela, como afirma Lenclud (1987).

Mas, apesar dessa semelhança pelos aspectos aludidos, podem os cemitérios ser considerados espaços museológicos? Ou teriam eles o potencial de serem? Partindo dessa ideia inicial, e com a intenção de refletir as indagações propostas, o presente artigo tem por objetivo comparar museu e cemitério, buscando entre eles correlações e aproximações.

Buscar-se-á apresentar e discutir o cemitério como espaço de construção de memória, bem como lugar que se ocupa da preservação e comunicação dessa memória para quem interage com esses espaços.

Por fim, defende que os cemitérios podem estar no cerne das discussões sobre o processo de musealização, pelo quantum de potencial museológico/documental que contém e que tal processo poderá contribuir para auxiliar na proteção, conservação e (re) valorização do espaço cemiterial - ainda hoje pouco compreendido e visto com certa ressalva, sobretudo no ocidente.

No intuito de lançar novo olhar e de igual modo discutir sobre o tema museu e cemitério por perspectiva inusual, tem o texto a sua razão de existir. Propõe-se uma forma de criar pontes mais sólidas entre as áreas de estudos e pesquisa, discutir e analisar os cemitérios como potenciais museus, ou seja, com a possibilidade de serem denominados em sua essência museus.

\section{QUE CONFIGURARIA ENTÃO UM MUSEU?}

Os museus na contemporaneidade, segundo o Estatuto de Museus instituído pela Lei n 11. 904/2009, são espaços que conservam, investigam, interpretam e comunicam as coleções de diversos valores, abertos as suas comunidades e sociedades e são, ainda, atualmente, definidos pelo Conselho Internacional de Museus (ICOM) como:

\begin{abstract}
Uma instituição permanente, sem fins lucrativos, ao serviço da comunidade e do seu desenvolvimento, aberto ao público, e que adquire, conserva, estuda, comunica e expõe testemunhos materiais do homem e do seu meio ambiente, tendo em vista o estudo, educação e fruição. (ICOM, 2004. Grifo nosso).
\end{abstract}

Em direção similar, Cury (2006) entende que, os museus, enquanto locais de preservação patrimonial, abarcam como funções basilares a coleta, pesquisa, documentação, conservação e comunicação, para fins de estudos e lazer, encadeamento esse que configura o processo de musealização.

Os autores Hernández e Tresseras (2007), por um prisma tipológico, afirmam que os museus podem ser classificados de acordo com as suas coleções que salvaguardam. Para o guia dos museus brasileiros do (IBRAM) os museus podem ser assim tipologizados: Antropologia e Etnografia; Arqueologia; Artes Visuais; Ciência e Tecnologia; História; Imagem e Som; Virtual; Biblioteconômico; Documental; Arquivístico; e das Ciências Naturais.

Quais seriam então os motivos essenciais para que um museu exista? Para responder tal indagação, parte-se do pensamento de Bottallo (1995), quando afirma que na contemporaneidade três são os motivos determinantes para que um museu exista: 1) a configuração de uma coleção; 2) a exposição de coleções; 3) as coleções devem ser observadas/vistas por um público.

Desenrolar-se-á esse pensamento ancorado em outros teóricos da área, que também nos ajudam a ampliar essa ideia. Senão, veja-se:

1. Não ha museu sem coleção. Ideia também reproduzida por Pearce (2005), ao dizer que as coleções são a parte central de um museu. São elas que distinguem os museus de outras instituições. "Essas coleções são a base a par- 
tir da qual se espraia a maioria das outras atividades de um museu" (PEARCE, 2005, p. 13).

2. Um museu que não comunica suas coleções e acervos não existe em sua função plena. Afirmação que também se pode respaldar em Cury (2006), quando observa que o processo museológico, que tem início na coleta, complementa seu sentido final na comunicação. A autora, na mesma obra, ainda diz que o sistema de comunicação museológico é o conjunto teórico que envolve todos os setores do museu para o seu desenvolvimento, por meio de exposições e ações educativas, colocadas como produtos dos sistemas em operação e a recepção de público. A importância da comunicação é colocada, ainda, por Roque (2010), ao dizer que “a comunicação no museu, a poética que este constrói em torno dos objetos que expõem, elaboram um novo modelo de fruição do patrimônio. Atribui-lhe, desta forma, a utilização que assegura o seu merecimento" (ROQUE, 2010, p. 48).

3. Não há museu sem público. Respaldado pela bibliografia da área - Koptcke (2012), Faria (2010), Cury (2006) dentre outros - afirma-se que a importância do público para o museu é essencial e indispensável para o desenvolvimento de suas atividades, sendo o público a razão da sua própria existência. Em última análise, não há museu sem público. Por último ancora-se em Guarnieri (2010), quando infere que os museus são locais criados pelo homem e para o homem, não havendo a possibilidade de imaginar o mundo onde se vive sem essas instituições, enquanto ainda se existe. "O museu tem sempre como sujeito e objeto o homem e seu ambiente, o homem e sua história, o homem e sua ideia e aspirações. Na verdade, o homem e a vida são sempre a verdadeira base do museu [...]" (GUARNIERI, 2010, p. 125).
Poder-se-ia, por oportuno, baseando-se no pensamento inicial da autora, acrescentar um quarto fator essencial para que um museu exista. 0 fato de uma coleção ou acervo, ou parte dele, ser representativo (reconhecimento), para a maioria do público que se comunica com o museu. Será que um museu que expõe apenas por expor, estará cumprindo sua função de agentes transformadores, espaço de aprendizagem, ou propício para a evocação de memórias e de afirmação identitária dos diferentes público? De partida, não. Por óbvio, nem todos os públicos que visitam um determinado museu irão se identificar com seu acervo ou coleção. Mas, afere-se aqui que um museu que não gere nenhum conhecimento, não evoque nenhuma memória, ou não ajude na afirmação de identidades, pelo público que interage com suas coleções, esse museu não existe em sua função plena (FIGURA 3).

Figura 3 - Motivos para que um museu exista

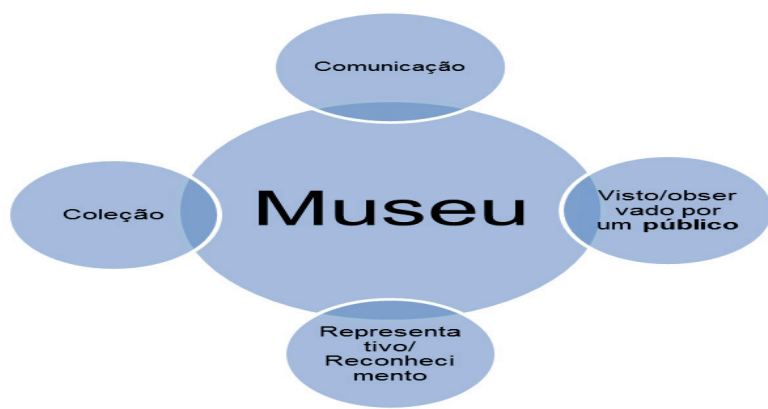

Fonte: Elaborado pelos autores (2015).

Talvez, nesse momento, a sua existência também possa ser questionada. 0 museu, em outros termos, precisa ser reconhecido, valorizado, ter uma importância para o público com quem dialoga, tanto no presente, como para as gerações vindouras. Percebe-se, então, que os museus contemporâneos têm por missão não apenas abrir suas portas, mas interagir, quebrar barreiras e abrir caminhos (GUIA ..., 2011); da mesma forma que permitir ao público a possibilidade de ampliar suas conexões por meio de novas experiências - sejam elas emotivas, cognitivas, sociais e educacionais (BOTALLO, 1995). Ou mesmo, por inter- 
médio de suas diferentes ferramentas comunicacionais, transformar-se "em um difusor de narrativas das coisas do homem e do mundo, propiciando a significação/ressignificação consigo, com o outro e com a realidade que o cerca" (FARIA, 2010, p. 345).

\section{CEMITÉRIO: 0 QUE SE ENTENDE POR ESSE LUGAR?}

De maneira concisa, pode-se dizer que cemitério é o espaço onde os humanos inumam os seus mortos. A prática da inumação - utilizada em grande escala mundo afora - foi adotada desde os primórdios da humanidade por povos e culturas distintas. Supõe-se que os primeiros sepultamentos (enterramentos) pré-históricos surgiram a partir da necessidade de depositar o cadáver em algum lugar seguro, devido ao problema causado pela decomposição dos corpos, seja numa cova ou num processo de inumação natural, dentro de uma gruta ou caverna (BAYARD, 1996, p. 41).

A palavra "cemitério" (do latim coemeterium, derivado do grego $\mu$, a partir do verbo $\mu$ ) designava, a princípio, o lugar onde se dormia, quarto, dormitório, pórtico para os peregrinos. Desse modo, cemitério passou a ter o sentido de local de descanso, onde o corpo repousa (BORGES, 2002, p. 128).

Fustel de Coulanges (2011 [1864]) delineia a gênese dos sepultamentos, embalsamamentos e cuidados com os mortos que surgem há milhares de anos com os povos chamados indo-europeus e, mais tarde, entre os etruscos, egípcios, romanos e gregos. Para ele, o cuidado com os mortos, que originou um verdadeiro culto aos antepassados durante a Antiguidade, legou à humanidade monumentos perenes como as pirâmides do Egito. 0 culto aos mortos, com o fim do paganismo e a propagação do cristianismo, foi aos poucos desaparecendo, para, na Idade Média, dar lugar a certo indiferentismo quanto aos cuidados do sepultamento e ao local da sepultura.

No fim do Medievo, a situação começa a mudar e, já no século XVIII, com as chamadas Luzes, a sociedade dita esclarecida passa a se importar mais com o desti- no dos corpos de seus mortos. Os sepultamentos, antes realizados nas Igrejas e pelas Igrejas - o que em Latim se dizia ad sanctos et apud ecclesiam -, começam a ser feitos nos cemitérios a céu aberto, em geral afastados das cidades, fora de seus muros. A justificativa dos iluministas e médicos sanitaristas para que os enterros não fossem nas Igrejas estava no temor de contaminação que os vivos poderiam sofrer pela proximidade, durante os ofícios religiosos e orações, dos gases e emanações pestilentas que se desprendiam dos cadáveres sepultados em grande quantidade no chão dos templos.

No Brasil, os cemitérios fora da Igreja surgiram no início do século XIX, quando os médicos, influenciados pelas ideias higienistas europeias, começaram a intervir nos setores da saúde pública. Essa mudança concorreu para que se generalizasse a opinião de que as Igrejas não eram o lugar apropriado para manter sepulturas. Determinou a construção de cemitérios ao ar livre e o mais longe possível do perímetro urbano. Isso se inicia em todas as grandes cidades europeias, nas décadas que precederam a Revolução Francesa, daí se propagando para todos os lugares. Portanto, a criação de cemitérios extramuros, inicialmente não estava associada à representação do status "post-mortem", mas a uma atitude de preservar o bem estar dos cidadãos, afastando os cadáveres do convívio direto, como acontecia nos salões das igrejas.

Uma nova mentalidade se instaura e é refletida na própria confecção dos túmulos: a imponência, a aura divina do morto sacralizado e ali jacente, tudo isso leva às visitações deles para oração e evocação do morto junto a Deus e aos Santos. Até a Renascença apenas os nobres e altas figuras eclesiásticas mereciam túmulos personalizados e com estátuas decorativas, a partir do século XIX a produção em escala industrial popularizou tal uso.

Com a disseminação dos cemitérios tradicionais seculares nas primeiras décadas do século XX, estes passaram a preservar em seus espaços uma arquitetura detentora de imagens eruditas e folclóricas, revelando representações estereotipadas dotadas de funcionalidade, valor artístico, simbólico e religioso. Os túmulos, então, harmonizaram-se, acentuando um 
sentimento nostálgico e afetuoso nesses locais, tornando esses cemitérios, além de um espaço religioso, uma instituição cultural.

Esses cemitérios logo passam a conter um acervo de túmulos de relevante qualidade artística, além de importantes personagens da história, arte e cultura brasileira. Acabam por se constituir espaços de memória, onde lápides registram fatos importantes e individualizam cada morto dentro de um conjunto.

Nesse contexto, os cemitérios podem ser compreendidos como o espaço onde a recusa pelo esquecimento é singular, sendo este um desejo do homem vivo: o homem não quer ser esquecido depois de morto e, por isso, "constrói” espaços determinados à sua perpetuação. A construção desses espaços exige o diálogo com as diferentes formas de controle simbólico do tempo e da individualização nas sociedades humanas, na busca de traduzir uma experiência e as relações com a cultura na qual se insere a vida post-mortem, onde os vivos e mortos dialogam a partir da carência dos primeiros e da herança dos últimos.

\section{CEMITÉRIOS E POTENCIAL MUSEOLÓGICO}

0 cemitério quando é pensado na perspectiva museológica requer reflexão, ainda que resumidamente, sobre as mudanças paradigmáticas mais recentes ocorridas no campo da museologia. E isto já se tentou delinear na primeira parte deste texto. Vai-se, agora, procurar as possíveis conexões entre os dois locais, as duas instituições: museu e cemitério.

Os cemitérios assim como os museus são espaços criados pelo sujeito e irão existir enquanto este perdurar. Ambos são lugares criados pelos e para os vivos. Por esse prisma, ressalta-se então que os cemitérios, quando musealizados, constituem mundo artificial ou um simulacro da realidade. "Os museus são caricaturas da realidade e não a realidade. Eles são projetos políticos e poéticos" (CHAGAS et al., 2008, p. 13).

Os cemitérios podem ter duas funções, em dada condição em que podem ser considerados um "hibrido": podem ser um simulacro da realidade, um espa- ço de representação, um patrimônio; por outro, além dessas características mencionadas, podem ainda desempenhar sua função original para o qual foi criado, que é a de ser local de regular inumação. Entretanto, os museus institucionalizados, via-de-regra, não podem desempenhar essa função. Seus acervos, a rigor, não costumam ser híbridos.

Importante grifar ainda que ambos, cemitérios e museus, possuem um acervo dotado de toda uma espiritualidade e simbolismo que envolve o público que os frequenta. Possibilita que esses, a partir de suas observações, criem conexões entre pessoas, lugares, tempos, objetos diversos. Tornando o invisível, visível, ou vice-versa. Podem então serem denominados semióforos, conforme aponta Pomian (1997).

Dessa mirada, os museus funcionam como espaços que fixam memórias, que freiam a inevitável rota do esquecimento; são lugares em que as pessoas podem, a partir do passado, articular e significar o presente, com o olhar projetado para o futuro. Os museus são, assim, como dobras no espaço-tempo, em que o passado se conecta com o presente, em que lugares longínquos são dispostos diante dos olhos, em que os mortos se comunicam com os vivos - tendo como plataforma de embarque as coleções.

Diferentemente da grande parte dos museus, em que suas coleções e acervos são deslocados de seu local de origem, sendo guardado em construções criadas ou adaptadas para tal fim, nos cemitérios, porém, esse cenário é diferente. Assim como em jardins botânicos, zoológicos, sítios arqueológicos, entre outros, nos cemitérios os visitantes também têm a possibilidade de apreciar os objetos in loco, pensados e utilizados para aquele fim. Com isso o diálogo e interação entre público e museu poderá se tornar um pouco menos complexo por meio de seu espaço físico (não descartando que as barreiras intelectuais possam ocorrer).

Quando se pretende que o visitante trabalhe como personagem interveniente e atuante, o espaço cemiterial musealizado deverá propor-se como elemento comunicador a todas as pessoas e reconhecer que, em definitivo, 0 seu discurso não seja unilateral, mas interativo. 
Definir-se-ão, existindo um espaço físico e limitado a partir do qual o visitante estabelece relações sensoriais imediatas, os percursos a partir de toda uma série de elementos encaixados em suas especificidades. Ou seja, quer-se considerar os objetos de cemitérios não alocados de forma aleatória, desconexa; mas, pensá-los dentro de um contexto, dentro de um esquema significativo projetado e interconectado. Trata de considerarem-se os objetos como parte de um discurso expositivo, em que se complementa com outras ferramentas museológicas (cores, espaço, legendas, símbolos, signos, entre outros), enquadramento e sequência dos elementos que compõem os interesses de cada roteiro, bem como a forma de interação do visitante, seduzindo-o ou repelindo-o.

0 público enxerga e experimenta o que the é oferecido dentro de determinados parâmetros previamente definidos pelos profissionais responsáveis. 0 percurso desse visitante é orientado a leva-lo a atingir, compreender e assimilar as propostas que o "museu" oferece ou, a partir de uma estrutura deixa-lo a elaborar o seu próprio percurso, discursos, e narrativa, enfim, ao apropriar e agregar outras visões as suas próprias na relação com a proposta expositiva do cemitério.

\section{CONSIDERACCÕES FINAIS}

Estabelecer relação entre o espaço cemiterial e o espaço museológico, demonstrando como e em que eles podem se correlacionar, implica em possibilitar ao cemitério uma transformação que vai para além de tê-lo como um elemento de serviço da sociedade, além daquele já intrínseco à sua existência, da cultura e da promoção turística; implicará na recuperação de sua importância social como espaço de encontro e convívio, prestando-se tanto à educação pública quanto às investigações etnológicas, econômicas, sociais, artísticas, entre outras. Em outros termos, significa encará-lo como documento da realidade da qual foi deslocado; e, neste caso, o deslocamento não é físico, mas simbólico. Implica vislumbrá-lo de sorte que o olhar do sujeito atravesse sua realidade física, projetando-o para um espectro significativo, portanto invisível ao olhar.

Para além das funções científicas, didáticas e pedagógicas e de sua importância no campo do turismo cultural, o "cemitério musealizado" poderá adquirir novo estatuto, tornando-se um marco patrimonial elemento referencial de cultura para a comunidade em que se integra, revelando-se à população um espaço de reconhecido valor cultural. Tal incremento, além de possibilitar a defesa de um patrimônio, buscará constituir, com base nos valores patrimoniais, agentes de desenvolvimento e valorização do cemitério e da promoção turística.

Para mencionar-se um exemplo de tal correlação e sua possível exploração (ainda que em tênue e ligeiro indicativo), fique-se com a comunicação museológi$\mathrm{ca/comunicação} \mathrm{cemiterial.} \mathrm{Esta} \mathrm{aconteceria} \mathrm{nos} \mathrm{"ca-}$ minhos" que a necrópole permite e nos olhares interrogativos e interpretativos sobre o todo e suas partes. Desse modo, o acervo-conjunto de objetos cemiteriais pode ser denominado - à semelhança dos museus como coleções, na compreensão da possibilidade de reagrupar os fracionamentos em busca de caminhos de interpretação. De outro ângulo, pode-se também entender esse cemitério-museu como lugar de problematizações e de muitos temas originados a partir de coleções e/ou de suas contextualizações, compondo um discurso expositivo entre elas, explorando assim a versatilidade, multiplicidade, pluralidade e a apropriação pública do patrimônio cultural.

Entende-se que os cemitérios funcionam como espelhos das aldeias, vilas ou cidades que os produzem. O conhecimento de qualquer comunidade ficará sempre incompleto se não incluir o seu cemitério. Por outro lado, viu-se que todo cemitério tem o potencial de ser um museu. $E$ todo cemitério que perpasse o processo de musealização, pode ser denominado como tal. Ou seja, um campo de memórias e de homenagens que oferece uma imensidão de elementos de trabalho e, que guarda e preserva objetos móveis e imóveis de arte de diferentes épocas que são sinais mais duradouros de atitudes e relações efemeramente existentes no mundo dos vivos. Que buscam assim como os museus, por 
fim último, a preservação de seus acervos, bem como de memórias e identidades dos diferentes grupos e sociedades a qual estão enraizados.

\section{REFERÊNCIAS}

BAYARD, Jean-Pierre. Sentido oculto dos ritos

funerários: morrer é morrer? São Paulo: Paulus, 1996.

BORGES, Maria E. Arte funerária no Brasil (18901930) ofício de marmoristas italianos em Ribeirão Preto = Funerary Art in Brazil (1890-1930): italian marble carver craft in Ribeirão preto. Belo Horizonte: C/Arte, 2002.

BOTTALLO, Marilúcia Os museus tradicionais na sociedade contemporânea: uma revisão. Revista do Museu de Arqueologia e Etnologia, São Paulo, n.5, p. 283-287, 1995.

BRASIL. Lei n⿳0 11.904, de 14 de janeiro de 2009. Disponível em: <http://www.planalto.gov.br/ ccivil_03/_Ato2007-2010/2009/Lei/L11904.htm>. Acesso em: 1 abr. 2015.

BRUNO, Maria C.O. Museus e pedagogia museológica: os caminhos para a administração dos indicadores da memória. In: MILDER, Saul Eduardo S. (Org.). As várias faces do patrimônio. Santa Maria: Pallotti, 2006. p.119-140.

CHAGAS, Mário S. et al. Sobre o Seminário Internacional e sua proposta no ano de 2008 A Democratização da Memória: A Função Social dos Museus Ibero- Americanos. In: CHAGAS, Mário de Souza; BEZERRA, Rafael Zamarano; BENCHETRIT, Sarah Fassa. (Org.). A democratização da memória: A função social dos museus Ibero- americanos. Rio de Janeiro: Museu Histórico Nacional, 2008. p.9-14.

COULANGES, Numa D.F. de A cidade antiga: estudos sobre o culto, o direito e as instituições da Grécia e de Roma. 2.ed. São Paulo: Revista dos Tribunais, 2011 [1864].

CURY, Marilia X. Exposição: concepção, montagem e avaliação. São Paulo: Annablume, 2006.

FARIA, Ana Carolina G. de. Exposições: do monólogo ao diálogo tendo como proposta de estímulo a mediação em museus. In: MAGALHÃES, Aline Montenegro; BEZERRA, Rafael Zamorano; BENCHETRIT, Sarah Fassa. (Org.). Museus e comunicação: exposições como objeto de estudo. Rio de Janeiro: Museu Histórico Nacional, 2010. p.345-356.

GUIA DOS MUSEUS BRASILEIROS. Disponível em: <http://www.museus.gov.br/wp-content/ uploads/2011/05/gmb_sudeste.pdf >. Acesso em: 1 abr. 2015.

HERNÁNDEZ, Josep B.; TRESSERAS, Jordi J. i. Património e museos en el presente. In: Gestión del Património Cultural. Barcelona: Ariel, 2007. p.59-79.

ICOM. Código de ética para Museus, 2004. Disponívelem<http://www.icom.org.br/sub. cfm?subicom=icom3\&canal=icom>. Acesso em: 10 mar. 2014.

KÖPTCKE, Luciana S. Público, o X da questão? A construção de uma agenda de pesquisa sobre os estudos de público no Brasil. Museologia \& Interdisciplinaridade. Revista do Programa de Pós-Graduação em Ciência da Informação da Universidade de Brasília, v.1, n.1, p.209-235, jan.-jul. de 2012

LENCLUD, Gerard. A Tradição não é mais o que era... Sobre as noções de tradição e de sociedade tradicional em etnologia. Revista História, histórias. Revista de Pós Graduação em história, Brasília, v.1, n.1, p.148-163, 2013. 
MOTA, Antonio. Museu da morte: patrimônios familiares e coleções. In: MAGALHÃES, Aline M.; BEZERRA, Rafael Z. (Org.). Museus nacionais e os desafios do contemporâneo. Rio de Janeiro: Museu Histórico Nacional, 2011. p.280-295.

NORA, Pierre. Entre memória e história: a problemática dos lugares. Revista Projeto História, v.10, p.7-28, 1993. Disponível em: <http://revistas. pucsp.br/index.php/revph/article/view/12101>. Acesso em: 25 jun. 2013.

PEARCE, Susan M. Pensando sobre os objetos. In: GRANATO, Marcus; SANTOS, Cláudia Penha dos (Org.). Museu: Instituição de Pesquisa. Rio de Janeiro: MAST, 2005. V.7. p.11-22.

POMIAN, Krzysztof. Coleção. In: VV. AA. Enciclopédia Einaudi 1: Memória-História. Lisboa: Imprensa Nacional Casa da Moeda, 1997. p.51-86.

ROQUE, Maria I. Comunicação no museu. In: MAGALHÃES, Aline Montenegro; BEZERRA, Rafael Zamorano; BENCHETRIT, Sarah Fassa. (Org.). Museus e comunicação: exposição como objeto de estudo. Rio de Janeiro: Museu Histórico, 2010. p.47-68. 